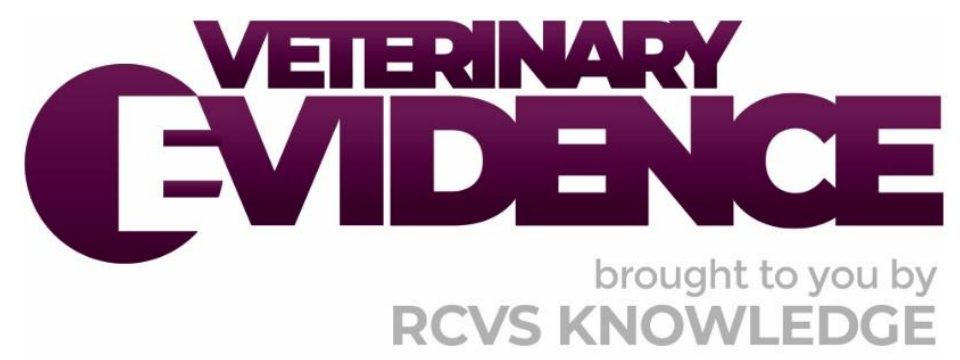

\title{
Reluxation Rates Following Different Techniques for Open Stabilisation of Feline Coxofemoral Dislocations
}

\section{A Knowledge Summary by}

Elly Russell MA, VetMB, Cert AVP, MRCVS ${ }^{1^{*}}$

\footnotetext{
${ }^{1}$ The Minster Veterinary Ptactice, Salisbury Road, York, YO26 4YN

*Corresponding Author (ellythevet@hotmail.com)
}

ISSN: 2396-9776

Published: 24 Jan 2019

in: Vol 4, Issue 1

DOI: http://dx.doi.org/10.18849/ve.v4i1.185

Reviewed by: Andy Morris (BSc(Hons) BVSc CertAVP(GSAS)

MRCVS) and Stephen Jones (MVB, MS, DACVS)

Next Review Date: Jan 24th 2021 


\section{KNOWLEDGE SUMMARY}

\section{PICO question}

In cats with craniodorsal coxofemoral luxation does surgical stabilisation using a toggle rod technique result in a lower rate of reluxation than using a transarticular pin?

\section{Clinical bottom line}

There is currently insufficient evidence to identify if transarticular pinning or a toggle rod technique result in lower rates of reluxation following surgical management of craniodorsal coxofemoral luxations in cats.

Both transarticular pinning and toggling using the Arthrex Mini TightRope system with Arthrex FiberWire suture resulted in $0 \%$ reluxation rates at short-term radiographic follow up with $0 / 20$ joints reluxated at 2-6 weeks post-transarticular pinning and $0 / 4$ joints reluxated at 6 weeks post-toggling.

Toggling using an IMEX toggle (IMEX Veterinary Inc.) and polydioxanone (PDS II, Ethicon) suture had a higher reluxation rate of $14 \%(2 / 14$ joints) at 3.5 to 6 weeks postsurgery.

Longer term follow up of joints stabilised using transarticular pinning found $16.6 \%$ reluxation ( $2 / 13$ joints) when radiographed at least 6 months after surgery.

Small sample sizes, and variations in the length of follow up, inclusion and exclusion criteria and surgical technique significantly challenges any conclusions that may be drawn.

It does appear that reluxation rates for all three techniques investigated here compare favourably to generally quoted reluxation rates following open reduction ( $28 \%$ quoted by Rochereau et al., 2012) and that the use of all reported techniques can be justified for the management of craniodorsal coxofemoral luxations in cats.

\section{Clinical Scenario}

A 4 kg 3-year-old male neutered domestic short-haired cat has been presented to you following a road traffic accident. After initial stabilisation, radiographs have identified a craniodorsal luxation of the right coxofemoral joint. Closed reduction was performed but the joint could not be maintained in reduction. No concurrent orthopaedic or other body system injuries have been identified. You advise the owners that surgical stabilisation would be the best course of action, particularly for a young active cat, and whilst the patient is not insured the owners are happy to make funds available for surgery at your practice. You have previously performed stabilisation of coxofemoral luxations in three feline patients using the transarticular pinning technique and whilst two patients recovered uneventfully, the third experienced reluxation. A colleague has recently attended a CPD course on treatment of common feline orthopaedic conditions and advises you that stabilisation using a toggle rod technique results in lower reluxation rates. You wonder which procedure should be performed in this case. 


\section{The evidence}

Three studies were identified which addressed the PICO question and fitted the inclusion and exclusion criteria applied. All the studies identified were noncomparative case series. The number of cases included in the studies was low: 4, 14 and 20 (median 14). Some other case series reporting outcomes for both feline and canine patients were excluded due to the low number of feline patients (three or less), along with a number of case reports.

All three studies described a surgical technique used for the open reduction and stabilisation of craniodorsal coxofemoral luxations in feline patients from a referral population. Two of the studies (Sissener et al., (2009) and Pratesi et al., (2012)) presented only feline patients, whilst Ash et al., (2012) presented findings for four feline patients and five small dogs. Only the results as they applied to the feline patients were considered. Sissener et al., (2009) described the use of transarticular pins $(1.6 \mathrm{~mm}$ diameter in the majority of cases with $1.2 \mathrm{~mm}$ and $2.0 \mathrm{~mm}$ pins also used) left in-situ for between 2 to 6 weeks in 20 cases. Radiographic follow up was performed at pin removal and, for 12 of the cases, at a time point $>6$ months postsurgery. No reluxations were identified at short-term follow up, but two patients radiographed $>6$ months later demonstrated reluxation. In addition to reluxation, complications included a bent $1.2 \mathrm{~mm}$ pin identified 6 weeks postoperatively in one patient and spontaneous resorption of the femoral head and neck identified 6 months postoperatively in another.

Pratesi et al., (2012) described a toggle rod technique used in 14 cases. A $3.2 \mathrm{~mm}$ IMEX toggle rod with two strands of 4 metric polydioxanone was used for the majority of cases. In two cases three strands of 4 metric polydioxanone were used and in one case the polydioxanone size was increased to 5 metric. A single case also had a smaller $2.7 \mathrm{~mm}$ toggle used. Short-term radiographic follow up was performed at 3.5-8 weeks postoperatively, revealing two patients had suffered reluxations. No other complications were reported. Ash et al., (2012) applied an identical technique to all four feline cases, using an Arthrex Mini TightRope toggle and Arthrex FiberWire suture. No reluxation was noted at 6 week postoperative radiographs and none of the feline patients experienced any other complications.

Reluxation rates including time of assessment for all three studies are summarised in the following table (Table 1):

\begin{tabular}{|c|c|c|c|}
\hline Technique & No reluxations/total hips & \% reluxation & Time reluxation assessed \\
\hline $\begin{array}{c}\text { Transarticular Pinning } \\
\text { (Sissener et al., 2009) }\end{array}$ & $0 / 20$ & $0 \%$ & $2-6$ weeks \\
\hline $\begin{array}{c}\text { Transarticular Pinning } \\
\text { (Sissener et al., 2009) } \\
\text { Long term follow up }\end{array}$ & $2 / 13$ & $16.6 \%$ & $>6$ months \\
\hline $\begin{array}{c}\text { Toggle Rod } \\
\text { (Pratesi et al., 2012) }\end{array}$ & $2 / 14$ & $14 \%$ & $3.5-8$ weeks \\
\hline $\begin{array}{c}\text { Toggle Rod using Arthrex } \\
\text { Mini TightRope } \\
\text { (Ash et al., 2012) }\end{array}$ & $0 / 4$ & $0 \%$ & 6 weeks \\
\hline
\end{tabular}

Table 1: Reluxation rates and assessment times for the 3 studies

All three studies also presented other, subjective, outcome measures that were not directly applicable to the PICO question. These included lameness assessments performed by a veterinarian and owner outcome questionnaires conducted by telephone. Along with the subjective nature of these assessments, all studies failed to describe observer standardisation, introducing observer bias, and time to follow up with owners varied widely introducing recall bias. 


\section{Summary of the evidence}

\begin{tabular}{|c|c|}
\hline Sissener et al., (2009) & \\
\hline Population: & $\begin{array}{l}\text { Feline patients presenting to two referral centres with craniodorsal } \\
\text { coxofemoral luxation and selected for surgical management using } \\
\text { transarticular pinning between } 1998 \text { and } 2003 . \\
\text { Selection criteria for use of this technique were: } \\
\text { 1. acute traumatic hip luxation that could not be reduced or } \\
\text { maintained in reduction } \\
\text { 2. hip luxation > } 3 \text { days OR recurrent reluxation following closed } \\
\text { reduction } \\
\text { 3. hip luxation presenting concurrently with other orthopaedic } \\
\text { injuries } \\
\text { 4. revision of failed previous surgical reduction. } \\
\text { This resulted in } 17 / 20 \text { patients with concurrent orthopaedic injuries, } \\
\text { two patients where closed reduction and Ehmer sling application had } \\
\text { failed and a final patient with no previous reduction attempts or } \\
\text { concurrent injuries. } \\
\text { Patients ranged from } 6 \text { months to } 12 \text { years. }\end{array}$ \\
\hline Sample size: & 20 cats ( 21 coxofemoral joints) $n=20$ \\
\hline Intervention details: & $\begin{array}{l}\text { - } 21 \text { coxofemoral joint luxations (19 unilateral, } 1 \text { bilateral) were } \\
\text { managed with open reduction and stabilisation using transarticular } \\
\text { pinning. } \\
\text { - A variety of methods were utilised for pin placement including } \\
\text { direct normograde pin placement, retrograde pre-drilling prior to } \\
\text { pin placement or normograde pre-drilling using a C guide. Hand- } \\
\text { chuck or power drill were used for pin placement. } \\
\text { - } 1 \times 1.2 \mathrm{~mm}, 17 \times 1.6 \mathrm{~mm} \text { and } 3 \times 2.0 \mathrm{~mm} \text { pins were placed with } \\
\text { estimation of pin size based on recommendations made in previous } \\
\text { reports of this technique in dogs. } \\
\text { - A greater trochanteric osteotomy was performed in one case. } \\
\text { Primary closure of the joint capsule is reported to have been } \\
\text { performed where possible. }\end{array}$ \\
\hline
\end{tabular}




\begin{tabular}{|c|c|}
\hline Study design: & Retrospective dual-centre case series \\
\hline Outcome studied: & $\begin{array}{l}\text { - Telephone questionnaire with owners } 21 \text { months (mean: range } 6- \\
66 \text { months) post-treatment. } \\
\text { - Outcome measures for owners's questionnaires were description of } \\
\text { cats gait, ability to jump, stiffness after rest or exercise, was cat } \\
\text { receiving any medication with owners and grading overall outcome. } \\
\text { - } 13 / 20 \text { cats were presented for physical examination by authors at } \\
\text { least } 6 \text { months post-treatment and outcome was graded: poor, fair, } \\
\text { good, very good or excellent based on criteria described by } \\
\text { Nunamaker (1973). } \\
\text { - } 19 / 20 \text { cats were radiographed prior to pin removal } 2-6 \text { weeks } \\
\text { postsurgery: maintenance of coxofemoral reduction was noted. } \\
\text { - } 12 / 20 \text { cats were radiographed at least } 6 \text { months following } \\
\text { treatment. Maintenance of coxofemoral reduction and presence of } \\
\text { degenerative joint disease were assessed. } \\
\text { - Overall outcome is reported as functional joint with intact } \\
\text { coxofemoral joint confirmed on radiography at least } 6 \text { months after } \\
\text { treatment. }\end{array}$ \\
\hline $\begin{array}{r}\text { Main findings: } \\
\text { (relevant to PICO question) }\end{array}$ & $\begin{array}{l}\text { - Overall success rate defined as a functional, intact coxofemoral joint } \\
\text { confirmed to have remained reduced at }>6 \text { months post-treatment } \\
\text { was } 77 \% \text { consisting of } 10 / 13 \text { joints radiographed }>6 \text { months } \\
\text { postsurgery that met this definition. } \\
\text { - Reluxation occurred in } 2 / 13 \text { joints presented for radiography }>6 \\
\text { months post-treatment giving a long term reluxation rate of } 15 \% \text {. } \\
\text { - } 1 / 13 \text { joints presented for radiography }>6 \text { months post-treatment } \\
\text { had experienced femoral head and neck resorption. } \\
\text { - Of the cats that presented for radiography and pin removal }(19 / 20) \\
2-6 \text { weeks post-treatment, all had maintained coxofemoral } \\
\text { reduction at this stage, resulting in a short-term relaxation rate of } \\
0 \% \text { (0/20 joints). } \\
\text { - The } 1.2 \text { mm pin was bent at time of pin removal. } \\
\text { - Owner outcome for patients with reluxations were both still graded } \\
\text { as very good. } \\
\text { - One patient was lost to any follow up with a total of eight patients } \\
\text { lost to long term follow up. }\end{array}$ \\
\hline
\end{tabular}




\begin{tabular}{|c|c|}
\hline Limitations: & $\begin{array}{l}\text { 5. Retrospective case series are a low level evidence on hierarchy of } \\
\text { evidence available. } \\
\text { - Noncomparative study. } \\
\text { - Referral population studied, so does not directly relate to clinical } \\
\text { scenario. } 17 / 20 \text { concurrent injuries. } \\
\text { - Some signalment details (weight and breed) which may be relevant } \\
\text { to outcome were not given in the study. } \\
\text { - No details of standardisation of veterinary surgeons, as a two centre } \\
\text { study. } \\
\text { - Also variation in size of pin selected and technique for placement. } \\
\text { - Both short and long-term radiographic follow up occurs at variable } \\
\text { time points. Mean follow up times are quoted, but given the wide } \\
\text { ranges, medians would be more appropriate. } \\
\text { - Radiograph observer is standardised for long-term follow up but not } \\
\text { short-term follow up. } \\
\text { - } 8 / 20 \text { cats lost to long term follow up. Given reluxation was } \\
\text { identified at long-term follow up but not short-term follow up, this } \\
\text { is significant. }\end{array}$ \\
\hline
\end{tabular}

2. Ash et al., (2012)

\begin{tabular}{|c|c|}
\hline Population: & $\begin{array}{l}\text { Feline and small canine patients presenting to a single referral centre } \\
\text { for management of traumatic craniodorsal coxofemoral luxation and } \\
\text { undergoing surgical stabilisation using a toggle technique (Arthrex } \\
\text { TightRope and Mini TightRope systems). } \\
\text { For feline patients, trauma to surgery ranged from 2-4 days, and } \\
\text { patients's weights ranged from } 3.7-4.7 \mathrm{~kg} \text {. All were domestic short- } \\
\text { haired cats. Presence of any concurrent injuries is not given. } \\
\text { Patients were excluded if there was radiographic evidence of } \\
\text { periarticular fractures, hip dysplasia or osteoarthritis. }\end{array}$ \\
\hline Sample size: & 4 felines and 5 canines $n=4$ relevant to PICO \\
\hline Intervention details: & $\begin{array}{l}\text { - All four feline patients had craniodorsal coxofemoral luxation } \\
\text { managed using surgical stabilisation with Arthrex Mini TightRope } \\
\text { toggle and Arthrex FiberWire suture. } \\
\text { - Postoperative management was standardised with enforced cage } \\
\text { rest for } 2 \text { weeks and unrestricted exercise after } 10 \text { weeks. } \\
\text { - No greater trochanter osteotomies are described and there is no } \\
\text { reference to primary closure of any remnants of joint capsule. }\end{array}$ \\
\hline Study design: & Retrospective single centre case series \\
\hline
\end{tabular}




\begin{tabular}{|c|c|}
\hline Outcome studied: & $\begin{array}{l}\text { - Number of days to postoperative weight bearing. } \\
\text { - Lameness evaluation performed } 2 \text { and } 6 \text { weeks postoperatively. } \\
\text { Scored } 0 \text { = normal gait, } 1 \text { = mild weight bearing lameness, } 2 \text { = } \\
\text { moderate weight bearing lameness, } 3 \text { = severe weight bearing } \\
\text { lameness, } 4 \text { = severe intermittent weight bearing lameness, } 5 \text { = } \\
\text { severe continuous non-weight bearing lameness. } \\
\text { - Radiographic (orthogonal views) follow up } 6 \text { weeks postoperatively. } \\
\text { - Telephone follow up with owners using standardised questionnaire } \\
\text { conducted } 16-44 \text { weeks postoperatively. } \\
\text { - Descriptive recording of complications. } \\
\text { - No loss to follow up. }\end{array}$ \\
\hline $\begin{array}{l}\text { Main findings: } \\
\text { (relevant to PICO question) }\end{array}$ & $\begin{array}{l}\text { - Radiographic follow up at } 6 \text { weeks postoperatively showed } \\
\text { unchanged quality of hip reduction and toggle position and absence } \\
\text { of periarticular osteophytosis or coxofemoral remodelling. } \\
\text { - Reluxation rate at } 6 \text { weeks postoperatively was therefore } 0 \% \text {. }\end{array}$ \\
\hline Limitations: & $\begin{array}{l}\text { - Retrospective case series are a low level of evidence on hierarchy of } \\
\text { - Nidence available. } \\
\text { - Inclusion criteria not clear with no detail of any concurrent injuries } \\
\text { given. } \\
\text { - Some signalment details including weight and age, which may be } \\
\text { relevant to outcome were not given in the study. } \\
\text { - Surgical procedure and postoperative care standardised but no } \\
\text { detail of the number of surgeons. } \\
\text { - Subjective outcome measures without observer standardisation. } \\
\text { - Wide range of follow up time, although quoting median time rather } \\
\text { than mean is helpful. } \\
\text { - Small sample size in target species. }\end{array}$ \\
\hline
\end{tabular}




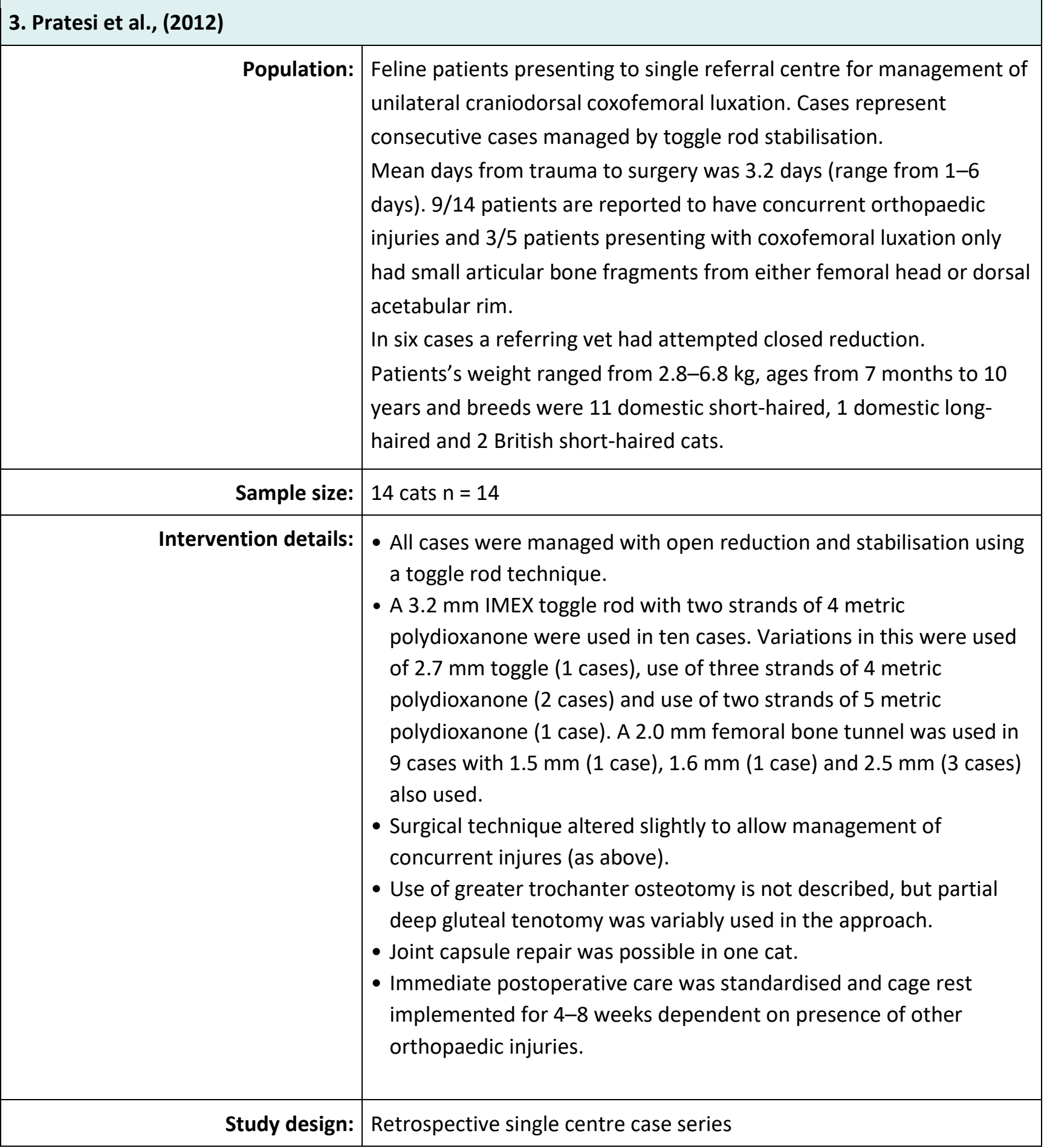




\begin{tabular}{|c|c|}
\hline Outcome studied: & $\begin{array}{l}\text { - Veterinary assessment and follow up radiographs performed 3.5-8 } \\
\text { weeks postoperatively. } \\
\text { - Clinical examination findings recorded were use of affected limb and } \\
\text { range of movement and hip stability assessed under sedation. } \\
\text { - Radiographs assessed maintenance of coxofemoral reduction and } \\
\text { percentage of pelvic canal narrowing due to presence of toggle rod. } \\
\text { - Telephone follow up was performed with } 11 / 13 \text { owners 4-42 } \\
\text { months postoperatively (mean follow up } 15.5 \text { months). Two } \\
\text { patients with coxofemoral reluxation at previous radiographic } \\
\text { assessment were excluded from this follow up. } \\
\text { - Details recorded were: time to achieve good use on operated leg, } \\
\text { use of any medication, use of litter tray and any concerns about } \\
\text { urination and defecation and an overall quality of life assessment } \\
\text { (poor, fair, good, very good or excellent). } \\
\text { - Owners also completed questionnaire designed to assess } \\
\text { degenerative joint disease associated pain with nine specific } \\
\text { functions and four behaviours assessed on five point scale. }\end{array}$ \\
\hline $\begin{array}{r}\text { Main findings: } \\
\text { (relevant to PICO question) }\end{array}$ & $\begin{array}{l}\text { - All cats were weight bearing on the affected limb the day after } \\
\text { - Rurgery. } \\
\text { - Radiography at } 3.5-8 \text { weeks postoperatively revealed reluxation in } \\
2 / 14 \text { cases, a } 14 \% \text { reluxation rate. } \\
\text { - For cats without reluxation, limb use was considered normal on } \\
\text { clinical exam, and hip stability and range of movement normal } \\
\text { under sedation. } \\
\text { - Good limb use despite reluxation was noted in these two cases. } \\
\text { - The } 11 \text { cats without reluxation had longer term follow up at } 15.5 \\
\text { months (mean time to follow up) by owner questionnaire. } 10 / 11 \\
\text { owners reported excellent quality of life for their cats and } 7 / 11 \\
\text { considered their cats to have normal limb function. }\end{array}$ \\
\hline
\end{tabular}




\begin{tabular}{|c|c|}
\hline Limitations: & $\begin{array}{l}\text { - Retrospective case series are a low level of evidence on hierarchy of } \\
\text { - } \text { - Nonidence available. } \\
\text { - Inclusion and exclusion criteria are not defined. } \\
\text { - Variability in surgical technique, although all surgeries were } \\
\text { performed by one of two boarded surgeons. } \\
\text { - Subjective outcome assessments including veterinary assessment, } \\
\text { radiographic assessment and owner survey. } \\
\text { - Details of observers of radiographic and veterinary assessment not } \\
\text { given. } \\
\text { - Time from surgery to owner survey is very variable (range 1.5-39 } \\
\text { months) and would be better expressed as median time to surgery } \\
\text { rather than mean. } \\
\text { - Two patients experiencing reluxation are excluded from long-term } \\
\text { follow up, and one further case is lost to longer-term follow up. }\end{array}$ \\
\hline
\end{tabular}

\section{Appraisal, application and reflection}

There is a lack of high quality evidence available to address the clinical question as all of the relevant studies identified and appraised here are retrospective case series. These sit low on the hierarchy of evidence and, particularly as they are not comparative studies, are not appropriate for assessing the impact of a specific surgical technique on outcome. Randomised, controlled, blinded studies that compare the two surgical techniques are needed to generate high quality evidence on which to base clinical decisions.

A large number of surgical stabilisation procedures are described for the management of coxofemoral luxation, but there is little evidence to guide technique choice (Moore, 2006). Reluxation is reported to be the most common complication following open reduction and surgical stabilisation of coxofemoral luxations. Rochereau et al., (2012) reports rates of around $28 \%$ for a variety of open reduction techniques including extra-articular stabilisation and ventral approach for the placement of stainless steel rope cases. It should be noted that many of the studies quoted examine reluxation rates for studies in dogs only. The reluxation rates quoted in all the studies (Table 1) appear to compare favourably with this, providing some evidence to support the use of these techniques. However, alongside the low case numbers, the variability in follow up time reduces the quality of information generated. In addition to this, none of the three studies described standardise the observer for short-term follow up radiographic assessments and whilst presence of coxofemoral luxation on a radiograph is relatively objective, observer bias is possible.

Longer-term radiographic follow up is only performed in the transarticular pinning study (Sissener et al., 2009). It is interesting that reluxation was first identified at least 6 months after surgery, at least 5 months after pin removal, in two cases. Ash et al., (2012) argues that 6 week follow up is adequate for assessing reluxation rates since long term periarticular fibrosis is responsible for stability after this stage and reluxation rates beyond this time frame are very low. However, the findings of the Sissener et al., (2009) study suggest that longer-term follow up is important in establishing reluxation rates. The evidence generated by these studies would be more valuable if follow up was standardised and long term, greater than 12 months, follow up was available for all the surgical techniques.

All of the studies identified describe management of cases at referral centres. This means the cases reported are unlikely to directly reflect those managed in the primary care setting. Specifically, cases are likely to have a higher incidence of concurrent injuries and for more time to have elapsed between luxation and treatment. Both of these factors might be expected to increase reluxation rates. Pre-surgical management is also variable and variably reported. Duration of luxation is not reported by Sissener et al., (2009) whilst prereferral management is not described by Ash et al., (2012). Postoperative care is also affected by 
management of concurrent injuries and therefore the patients in these studies are not always subject to the same postoperative management, which would be expected to impact on reluxation rates.

Differences in inclusion and exclusion critera, or the lack of these criteria, across the studies compromises the ability to compare reluxation rates for the different surgical procedures. Ash et al., (2012) excludes patients with radiographic evidence of periarticular fracture, hip dysplasia or osteoarthritis whilst Pratesi et al., (2012) includes two patients with suspected pre-existing hip dysplasia (HD) and three with periarticular bone fragments. Sissener et al., (2009) details inclusion criteria including concurrent injuries and failure of previous surgical stabilisation but does not mention HD or periarticular fractures. It is interesting to note that one of the 2/14 cases experiencing reluxation in the Pratesi et al., (2012) study had hip dysplasia since pre-existing pathology such as this might be expected to impact upon the success of open reduction and stabilisation of traumatic luxations. For this reason, inclusion of these cases in the Pratesi et al., (2012) and possibly in the Sissener et al., (2009) study limits the conclusions we can draw on reluxation rates from these studies.

For the transarticular pinning technique, accurate placement of the transarticular pin is crucial for correct seating of the femoral head in the acetabulum, which is very likely to correlate with reluxation rates. Sissener et al., (2009) reports three separate methods for pin placement were used, it would be useful to assess if any of these methods resulted in a better outcome. Similarly, pin size selection is poorly described and weight, which we would expect to guide size selection, is omitted from signalment. Evidence to guide pin size selection and placement technique would be useful but is lacking.

For the toggle techniques, Pratesi et al., (2012) uses different toggle sizes, suture sizes and thread numbers. Reasons for these variations are not always stated (although one patient received three strands of suture due to suspected pre-existing HD) and there is no obvious trend, for example increasing suture size or number with increasing patient weight. Again, the variation in surgical technique limits the conclusions we are able to draw about reluxation rates, and the study fails to generate guidelines for selection of toggle size or suture.

The surgical technique described by Ash et al., (2012) is consistently applied across all cases, which allows better assessment of the procedure's impact on reluxation rates. The toggle system reported by Pratesi et al., (2012) used both different toggle (Arthrex Mini- TightRope) and suture (Arthrex FiberWire) than the Ash et al., (2012) study. Suture type/strength and toggle construct are likely to impact upon reluxation rates. This limits the potential to combine data about 'toggle procedures' from these two studies (Ash et al., 2012 and Pratesi et al., 2012). Further, this difference in suture material highlights again the need for longer-term follow up, since polydioxanone utilised in the Pratesi et al., (2012) study will lose tensile strength at around 3-4 weeks, whilst the Arthrex FiberWire is more durable. The discovery of reluxation $>6$ months postoperatively (Sissener et al., 2009) might suggest that maintaining reduction requires more persistent implants and that periarticular fibrosis alone may be insufficient.

It should be noted that Sissener et al., (2009) reports owner outcomes for the patients with reluxations $>6$ months postoperatively to be very good and Pratesi et al., (2012) describes limb use as good despite reluxation within 6 weeks of surgery in two cases, one of which received no further treatment. It is important to consider if reluxation is the most clinically useful outcome measure. All the studies include other outcome measures, all subjective, including veterinary lameness assessments without observer standardisation and owner questionnaires completed at very wide ranging time points. Long-term degenerative joint disease may be a more important clinical comparator between surgical techniques and more objective outcome measures such as measuring ground reaction force on pressure sensitive walkways (Schnabl et al., 2015) could be considered.

In general, the studies fail to generate any descriptive rationale for the selection of one surgical procedure over another. All the cases in the Ash et al., (2012) study seem to have been managed using the toggle technique, and similarly in the Sissener et al., (2009) study for the pinning technique, whilst Pratesi et al., (2012) implies not all presenting cases were managed with the toggle technique but does not explain the choice of this technique for these cases.

Further studies using randomised, controlled, blinded trials comparing two standardised surgical techniques, ideally in a primary care setting, with objective outcome measures are needed. 
Methodology Section

\begin{tabular}{|c|c|}
\hline \multicolumn{2}{|l|}{ Search Strategy } \\
\hline $\begin{array}{r}\text { Databases searched and dates } \\
\text { covered: }\end{array}$ & $\begin{array}{l}\text { CAB Abstracts on CABI direct platform } 1973 \text { to week } 82018 \\
\text { MEDLINE on OVID platform } 1946 \text { to week } 82018 \\
\text { Scopus } 1973 \text { to week } 82018 \\
\text { Web of Science } 1973 \text { to week } 82018\end{array}$ \\
\hline Search terms: & $\begin{array}{l}\text { (cat OR cats OR feline OR felines) AND (hip dislocation OR hip } \\
\text { luxation OR coxofemoral dislocation OR coxofemoral luxation) AND } \\
\text { (transartic* OR transtroch* OR pin* OR togg* OR rod) }\end{array}$ \\
\hline Dates searches performed: & 25th Feb 2018 \\
\hline
\end{tabular}

\begin{tabular}{|c|c|}
\hline \multicolumn{2}{|l|}{ Exclusion / Inclusion Criteria } \\
\hline Exclusion: & $\begin{array}{l}\text { - wrong species } \\
\text { - luxation not craniodorsal } \\
\text { - surgical technique not recognisable as transarticular pinning or } \\
\text { toggle rod } \\
\text { - reluxation not given as outcome measure } \\
\text { - not English language } \\
\text { - conference proceedings } \\
\text { - review articles } \\
\text { - case reports or case series with }<3 \text { feline cases }\end{array}$ \\
\hline Inclusion: & $\begin{array}{l}\text { Correct species, craniodorsal luxation managed surgically with } \\
\text { technique recognisable as transarticular pinning or toggle rod with } \\
\text { outcome measures including reluxation. }\end{array}$ \\
\hline
\end{tabular}




\begin{tabular}{|c|c|c|c|c|c|c|}
\hline \multicolumn{7}{|l|}{ Search Outcome } \\
\hline Database & $\begin{array}{l}\text { Number } \\
\text { of results }\end{array}$ & $\begin{array}{l}\text { Excluded - } \\
\text { non- } \\
\text { English } \\
\text { language } \\
\text { publication }\end{array}$ & $\begin{array}{l}\text { Excluded - } \\
\text { Case reports, } \\
\text { Reviews, } \\
\text { Conference } \\
\text { proceedings }\end{array}$ & $\begin{array}{c}\text { Excluded - } \\
\text { Does not } \\
\text { address PICO } \\
\text { question }\end{array}$ & $\begin{array}{c}\text { Excluded - Full } \\
\text { text not } \\
\text { available }\end{array}$ & $\begin{array}{c}\text { Total } \\
\text { relevant } \\
\text { papers }\end{array}$ \\
\hline CAB Abs & 21 & 6 & 5 & 7 & 1 & 2 \\
\hline MEDLINE & 14 & 1 & 1 & 9 & 1 & 2 \\
\hline Scopus & 8 & 2 & 1 & 3 & 0 & 2 \\
\hline Web of Science & 38 & 7 & 3 & 25 & 0 & 3 \\
\hline \multicolumn{6}{|c|}{ Total relevant papers when duplicates removed } & 3 \\
\hline
\end{tabular}

\section{CONFLICT OF INTEREST}

The author declares no conflict of interest.

\section{REFERENCES}

1. Ash, K., Rosselli, D., Danielski, A., Farrel, M., Hamilton, M. \& Fitzpatrick, N. (2012) Correction of craniodorsal coxofemoral luxation in cats and small breed dogs using a modified Knowles technique with the braided polyblend TightRope systems. Vet Comp Ortho Traumatol, 25 (1), pp. 54 -

60. http://dx.doi.org/10.3415/VCOT-11-02-0019

2. Nunamaker, D. M. (1973) Repair of femoral head and neck fractures by interfragmentary compression. JAVMA,162, 569-572

3. Moore, A. (2006) Decision making in the management of hip luxations in dogs and cats. In Practice, 28 (10), pp. 570-576. http://dx.doi.org/10.1136/inpract.28.10.570

4. Pratesi, A., Grierson, J. \& Moores, A. (2012) Toggle rod stabilisation of coxofemoral luxation in 14 cats. JSAP, 53 (5), pp. 260-266. https://doi.org/10.1111/j.1748-5827.2012.01199.x

5. Rochereau, P. \& Bernardé, A. (2012) Stabilization of coxofemoral luxation using tenodesis of the deep gluteal muscle. Technique description and reluxation rate in 65 dogs and cats (1995-2008). Vet Comp Ortho Traumatol, 25 (1), pp. 49-53. 
6. Schnabl, E. \& Bockstahler, B. (2015) Systematic review of ground reaction force measurements in cats. The Veterinary Journal, 206 (1), pp. 83-90. http://dx.doi.org/10.1016/j.tvjl.2015.05.017

7. Sissener, T.R., Whitelock, R.G. \& Langley-Hobbs, S, (2009) Long-term results of transarticular pinning for surgical stabilisation of coxofemoral luxation in 20 cats. JSAP, 50 (3), pp. 112-

7. http://dx.doi.org/10.1111/j.1748-5827.2008.00625.x 


\section{EVIIDEFeE

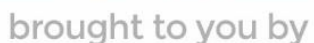 \\ RCVS KNOWLEDGE}

\section{Intellectual Property Rights}

Authors of Knowledge Summaries submitted to RCVS Knowledge for publication will retain copyright in their work, and will be required to grant RCVS Knowledge a non-exclusive license of the rights of copyright in the materials including but not limited to the right to publish, republish, transmit, sell, distribute and otherwise use the materials in all languages and all media throughout the world, and to license or permit others to do so.

\section{Disclaimer}

Knowledge Summaries are a peer-reviewed article type which aims to answer a clinical question based on the best available current evidence. It does not override the responsibility

of the practitioner. Informed decisions should be made by considering such factors as individual clinical expertise and judgement along with patient's circumstances and owners' values. Knowledge Summaries are a resource to help inform and any opinions expressed within the Knowledge Summaries are the author's own and do not necessarily reflect the view of the RCVS Knowledge. Authors are responsible for the accuracy of the content. While the

Editor and Publisher believe that all content herein are in accord with current recommendations and practice at the time of publication, they accept no legal responsibility

for any errors or omissions, and make no warranty, express or implied, with respect to material contained within.

For further information please refer to our Terms of Use.

RCVS Knowledge is the independent charity associated with the Royal College of Veterinary Surgeons (RCVS). Our ambition is to become a global intermediary for evidence based veterinary knowledge by providing access to information

that is of immediate value to practicing veterinary professionals and directly contributes to evidence based clinical decision-making.

\section{https://www.veterinaryevidence.org/}

RCVS Knowledge is a registered Charity No. 230886.

Registered as a Company limited by guarantee in England and Wales No. 598443.

Registered Office: Belgravia House, 62-64 Horseferry Road, London SW1P 2AF

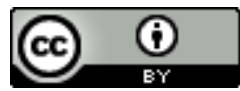

This work is licensed under a Creative Commons Attribution 4.0 International License. 